\title{
Bootstrap Approach to Comparison of Alternative Methods of Parameter Estimation of a Simultaneous Equation Model
}

\author{
Olubusoye, O. E., J. O. Olaomi, and O. O. Odetunde
}

\begin{abstract}
A bootstrap simulation approach was used to generate values for endogenous variables of a simultaneous equation model popularly known as Keynesian Model of Income Determination. Three sample sizes 20, 30 and 40 each replicated 10, 20 and 30 times were considered. Four different estimation techniques: Ordinary Least Square (OLS); Indirect Least Square (ILS); Two-Stage Least Square (2SLS) and Full Information Maximum Likelihood (FIML) methods were employed to estimate the parameters of the model. The estimators were then evaluated using the average parameter estimates; absolute bias of the estimates and the root mean square error of the estimates. The result shows that generally, ILS provided the best estimates.
\end{abstract}

Keywords: Bootstrap, endogenous, exogenous, least squares, maximum likelihood.

\section{Introduction}

A fundamental task of quantitative social science research is to make probability-based inferences about a population characteristic, say $\theta$, based on an estimator, $\hat{\theta}$, using a sample drawn from that population. Bootstrapping is a computationally intensive, non-parametric technique for making such inferences. Bootstrapping differs from the traditionally parametric approach to inference in that it employs large numbers of repetitive computations to estimate the shape of a statistic's sampling distribution, rather than strong distributional assumptions and analytical formulas (Mooney et al, 1993). 
Unlike single equation model, simultaneous equation model was a true representation of two-way directional cause-and -effect relationship that existed between economic variables. Since simultaneous equation model has a wide application in real life situation most especially in various economic phenomena, hence, in this study we investigated the relative performance of four estimators of a simultaneous equation model with the objectives of examining the relative performance of selected estimation techniques, examining the sensitivity of the estimates to increasing sample sizes (i.e. asymptotic effect) and examining the sensitivity of the result to increasing levels of replication, which explains the stability of results.

\section{Model Presentation and Its Basic Assumptions}

The paper considered a two-equation model often referred to as Keynesian Model of Income Determination. The model consisted of one structural equation and one identity equation. The specification was given as follows:

$$
\begin{gathered}
C_{t}=\alpha+\beta y_{t}+U_{t} \\
0<\beta<1 \\
y_{t}=C_{t}+I_{t}
\end{gathered}
$$

where $\mathrm{C}$ was the consumption expenditure; $\mathrm{Y}$ was the income; I was the investment (assumed exogenous); $\mathrm{t}$ was the time; $\mathrm{U}$ was the stochastic disturbance term and $\alpha \& \beta$ are the parameters of the model.

In the linear simultaneous equation economic model containing $G$ endogenous (jointly dependent) variables $\mathrm{y}_{1}, \ldots . \mathrm{y}_{\mathrm{G}}$ and $\mathrm{K}$ predetermined variables $\mathrm{X}_{1}, \mathrm{X}_{2}, \ldots, \mathrm{X}_{\mathrm{k}}$ the $\mathrm{G}$ structural equations at time $t$ may in general be written as: 
$\beta_{i 1} y_{1 t}+\beta_{i 2} y_{2 t}+\ldots+\beta_{i G} y_{G t}+\gamma_{i 1} X_{1 t}+\ldots \gamma_{i k} X_{k t}$
$i=1, \ldots . G, t=1, \ldots, n \ldots$. In matrix form, (1.3.1) can be written as

$$
B y_{t}+\Gamma X_{t}=U_{t}
$$

where $B$ was a $G \times$ matrix of coefficients of current endogenous variables, $\Gamma$ is a $\mathrm{G} \times \mathrm{K}$ matrix of coefficients of predetermined variables, $Y_{t}, X_{t}$ and $U_{t}$ were column vectors of $G, K$ and $G$ elements respectively.

$$
\begin{aligned}
& \mathrm{B}=\left(\begin{array}{ccc}
\beta_{11} & \beta_{12} \ldots & \beta_{1 \mathrm{G}} \\
\beta_{21} & \beta_{22} \ldots & \beta_{2 \mathrm{G}} \\
\beta_{\mathrm{G} 1} & \beta_{\mathrm{G} 2} \ldots & \beta_{\mathrm{GG}}
\end{array}\right) \Gamma\left(\begin{array}{ccc}
\gamma_{11} & \gamma_{12} \ldots & \gamma_{1 \mathrm{~K}} \\
\gamma_{21} & \gamma_{22} \ldots & \gamma_{2 \mathrm{~K}} \\
\gamma_{\mathrm{G} 1} & \gamma_{\mathrm{G} 2} \ldots & \gamma_{\mathrm{GK}}
\end{array}\right) \\
& \mathrm{Y}_{\mathrm{t}}=\left(\begin{array}{c}
\mathrm{Y}_{1 \mathrm{t}} \\
\mathrm{Y}_{2 \mathrm{t}} \\
\cdot \\
\mathrm{Y}_{\mathrm{Gt}}
\end{array}\right) \mathrm{X}_{\mathrm{t}}=\left(\begin{array}{c}
\mathrm{X}_{1 \mathrm{t}} \\
\mathrm{X}_{2 \mathrm{t}} \\
\cdot \\
\\
\dot{\mathrm{X}}_{\mathrm{Kt}}
\end{array}\right) \mathrm{U}_{\mathrm{t}}=\left(\begin{array}{c}
\mathrm{U}_{1 \mathrm{t}} \\
\mathrm{U}_{2 \mathrm{t}} \\
\cdot \\
\mathrm{U}_{\mathrm{Gt}}
\end{array}\right)
\end{aligned}
$$

The system of equations was complete since the number of endogenous variables is equal to the number of structural equations in 
the model. Each equation in Equation (1.3.2) has $\mathrm{G}+\mathrm{K}$ parameters, $\beta_{\mathrm{i} 1}, \quad \beta_{\mathrm{i} 2} \ldots . \beta_{\mathrm{iG}}, \gamma_{\mathrm{i} 1}, \gamma_{\mathrm{i} 2}, \ldots ., \gamma_{\mathrm{iK}} .$. In practice, some of the parameters were usually specified to be zero. Otherwise, all the equations in the model will look alike statistically, and no equation would be identified. Constant terms were assumed to be included in the model by specifying one of the predetermined variables to be identically unity. The basic assumptions included the following:

a. The vector of sample observations on Y may be expressed as a linear combination of the sample observations on the explanatory $\mathrm{X}$ variables plus a disturbance vector. The central problem is to obtain estimates of the unknown $B$ and $\Gamma$ matrices.

b. The explanatory variables did not form a linearly dependent set. Alternatively, $\mathrm{X}$ matrix is of full column rank i.e $\rho(X)=\mathrm{k}$ where $\mathrm{k}$ was the number of explanatory variables.

c. X was a non-stochastic matrix.

d. For an arbitrary period $t$,

$$
\mathrm{E}\left(\mathrm{U}_{\mathrm{t}}\right)=0
$$

Variance-covariance matrix of $\mathrm{U}$ was defined as

$$
\mathrm{E}\left({ }_{t}{ }_{t}{ }_{t}^{\prime}\right)=\Sigma=\Omega \otimes I_{n}
$$

e. The vector $U$ has a multivariate normal distribution.

\section{Methodology}

A typical bootstrap experiment takes the following form:

Assume the econometric model, say

$$
\mathrm{Y}=\mathrm{F}(\mathrm{I}, \theta)+\mathrm{U}
$$


Where $\mathrm{U} \sim \mathrm{N}\left(0, \sigma^{2}\right)$ and also satisfies other classical assumptions for least squares estimation. Numerical values were assigned to all the parameters embodied in the vector $\theta$. In this study, the vector $\theta$ consisted of parameters $\alpha$ and $\beta$ which assumed values 1.0 and 0.5 respectively. The variance $\sigma^{2}$ was also assigned a numerical value, and on the basis of the assumed $\sigma^{2}$, the disturbance term, $U$ is generated. Throughout the experiment we assume $\sigma^{2}=1$.

A random sample of size $\mathrm{T}$ of I was selected from a pool of uniformly distributed random numbers with interval $(0,1)$ and the numerical values of $F(I, \theta)$ are computed. The vector $Y$ was then obtained by computing $\mathrm{F}(\mathrm{I}, \theta)+\mathrm{U}$. This was most conveniently done by using reduced form of the model. Then the regression of $\mathrm{Y}$ on $\mathrm{I}$ is performed to produce estimate $\hat{\theta}$ of $\theta$. We set sample size $\mathrm{T}=20,30$ and 40 for the purpose of the study.

Using the bootstrap software package, the sample of $U$ generated was bootstrapped many times, say 1000 times and this was replicated in $r$ times. Each replication produces a bootstrapped sample which gave distinct values of Y. This leads to having different estimates $\hat{\theta}$ of $\theta$ for each bootstrapped sample from several regression of $\mathrm{Y}$ on fixed I. Thus, it was possible for the sampling distribution of $\hat{\theta}$ to be constructed. The empirical distribution so obtained was then utilized in evaluating the precision of $\hat{\theta}$ and in making other comparisons especially of the relative performance of different estimators of $\hat{\theta}$. The procedure described above is then repeated for different sample sizes $\mathrm{T}$ over various levels of replication $\mathrm{r}$ to investigate asymptotic effects and the stability of the results. 


\section{Results and Discussion}

The outcomes of the bootstrap experiment were subjected to analysis using Time Series Processor (TSP 5.0) software package. Considering three sample sizes $\mathrm{T}=20,30$ and 40 each at four levels of replication $r=10,20,30$ and 40, we provide results on the performance of four estimators using these three criterion.

(i). Average or Mean of Estimates in comparison with the true parameter value.

Let $\hat{\theta}_{i}$ be the estimates of the parameter $\theta$ obtained in the ith bootstrap replication. We compute

$$
\bar{\theta}=\frac{1}{B} \sum_{i=1}^{B} \hat{\theta}_{i} \text {, where } \mathrm{B}=\text { number of bootstrap }
$$

replication

(ii). Bias of Estimates

$$
\operatorname{Bias}(\hat{\theta})=\bar{\theta}-\theta
$$

(iii). Root Mean Square Error (RMSE)

$$
\begin{aligned}
\operatorname{RMSE} & (\hat{\theta})=\sqrt{M S E(\hat{\theta})} \\
& =\sqrt{\operatorname{Var}(\hat{\theta})+[\operatorname{Bias}(\hat{\theta})]^{2}}
\end{aligned}
$$


where

$$
\operatorname{MSE}(\hat{\theta})=B^{-1} \sum_{i=1}^{B}(\hat{\theta}-\theta)^{2}
$$

and

$$
\operatorname{Variance}(\hat{\theta})=B^{-1} \sum_{i=1}^{B}\left(\hat{\theta}_{i}-\bar{\theta}\right)^{2}
$$

The paper used the following estimation techniques in estimating the parameters of the model: Ordinary Least Square Method (OLS), Indirect Least Square Method (ILS), Two-Stage Least Square Method (2SLS) and Full Information Maximum Likelihood Method (FIML)

The results obtained were summarized in the following tables 1 to 3 . The Tables consist of the results of the analysis based on the three criterion used to examine the performance of the estimators. 12 cases were considered for each of the criteria using 3 sample sizes and 4 levels of replication.

Table 1 presented the average of estimates at various sample sizes over 4 levels of replication. These average values are presented for each of the estimators. Best estimators are those whose average estimates are close to the true parameters. In this table under parameter $\alpha$, the best estimator was ILS because it produces best estimates in 5 cases out of 12 cases considered. 2SLS was best in 4 cases while FIML was best in 3 cases. Also, under parameter $\beta$, ILS was best in 9 of the 12 cases. 2SLS followed with a distant margin, being best in only 3 cases.

Table 2 presented the absolute bias of the parameter estimates. The best estimators were those with the least absolute biases. For $\alpha$, ILS generated lower biases than other estimators in 5 cases. Hence it was the best estimator. It was followed by 2SLS and then FIML which 
generated lower biases than other estimators in 3 cases. For $\beta$, ILS also performed best by producing least biases in 9 cases out of the 12 cases considered. It is followed by 2SLS with a distant margin.

Table 3 presented the root mean square error of parameter estimates. The smaller the root mean square error, the better the performance of the estimator, for parameter $\alpha$, FIML performed best in 5 cases while 2SLS closely followed in 4 cases. ILS was best in 3 cases. For parameter $\beta$, however, ILS clearly takes the lead by performing best in 7 cases. FIML followed with a distant margin of 4 cases while 2SLS is best in only 1 case.

\section{Conclusion}

This study has shown that ILS was superior to other estimators in estimating the parameters of just identified equations of a simultaneous equation model. However, this superiority was displaced in some cases by 2SLS and FIML (especially for parameter $\alpha$ ). ILS is noticeably overwhelmingly superior in estimating both parameters. Furthermore, it was observed that the results were relatively stable at various levels of replication when sample sizes are kept constant. Finally, there was no remarkable asymptotic effect on the performance of the estimators. 


\section{References}

Diaconis. P., \& Efron, B.(1983, May): "Computer Intensive Methods in Statistics", Scientific American, 248, 96 - 108.

Efron, B. (1979). "Bootstrap Methods: Another look at the Jackknife." Annals of Statistics, 7(1), $1-26$.

Kousoyiannis, A (1977): Theory of Econometrics, Second edition, Macmillan Press.

Mooney, C. Z. and Duval, R.D. (1993): Bootstrapping: A Non-Parametric Approximation to Statistical Inference, London: Sage Publications

Michael Wood (2005): "Bootsrapped Confidence Intervals as an Approach to Statistical Inference", Organizational Research Methods, Vol. 8 No. 4, October 2005, 454-470.

Wood, M. (2003): Making Sense of Statistics: A non-Mathematical Approach. Basingstoke, UK: Palgrave.

Table 1: Performance Evaluation of Estimators Using Average Parameter Estimates

\begin{tabular}{|c|c|c|c|c|c|c|c|}
\hline \multirow[t]{2}{*}{ Estimator } & \multirow{2}{*}{$\begin{array}{l}\text { Replica- } \\
\text { tion }\end{array}$} & \multicolumn{2}{|l|}{$\mathrm{T}=20$} & \multicolumn{2}{|l|}{$\mathrm{T}=30$} & \multirow{2}{*}{$\begin{array}{c}\mathrm{T}=40 \\
\boldsymbol{\alpha}_{(1.0)}\end{array}$} & \multirow[b]{2}{*}{$\beta_{(0.5)}$} \\
\hline & & $\alpha_{(1.0)}$ & $\beta_{(0.5)}$ & $\alpha_{(1.0)}$ & $\beta_{(0.5)}$ & & \\
\hline \multirow[t]{4}{*}{ OLS } & 10 & 1.8329 & 1.6052 & 2.1045 & 0.7736 & 1.7504 & 1.1310 \\
\hline & 20 & 1.7215 & 1.6603 & 1.8382 & 1.2280 & 1.8247 & 1.2556 \\
\hline & 30 & 1.8444 & 1.4633 & 1.8995 & 1.0995 & 1.7861 & 1.2934 \\
\hline & 40 & 1.9940 & 1.4123 & 1.8621 & 1.2133 & 1.8401 & 1.2819 \\
\hline \multirow[t]{4}{*}{ ILS } & 10 & 0.8754 & 0.5623 & 1.2887 & 0.4121 & 0.9211 & 0.4991 \\
\hline & 20 & 0.9103 & 0.5317 & 1.0039 & 0.4909 & 0.9520 & 0.5115 \\
\hline & 30 & 1.0370 & 0.4922 & 1.0133 & 0.4881 & 0.9397 & 0.5127 \\
\hline & 40 & 1.0619 & 0.4881 & 0.9763 & 0.5049 & 0.9685 & 0.5080 \\
\hline \multirow[t]{4}{*}{2 SLS } & 10 & 0.7728 & 0.5880 & 1.3500 & 0.3775 & 0.9369 & 0.4895 \\
\hline & 20 & 0.7990 & 0.5673 & 1.0876 & 0.4705 & 0.9592 & 0.5005 \\
\hline & 30 & 0.9276 & 0.5192 & 1.0974 & 0.4546 & 0.9740 & 0.4990 \\
\hline & 40 & 1.0229 & 0.5021 & 1.1436 & 0.4444 & 0.9107 & 0.5264 \\
\hline \multirow[t]{4}{*}{ FIML } & 10 & 0.6346 & 0.6115 & 1.2478 & 0.3854 & 0.8955 & 0.5090 \\
\hline & 20 & 0.6744 & 0.5978 & 1.0066 & 0.4772 & 0.9496 & 0.5050 \\
\hline & 30 & 0.8496 & 0.5596 & 1.0027 & 0.4620 & 0.8702 & 0.4931 \\
\hline & 40 & 0.9068 & 0.5371 & 0.9848 & 0.4690 & 0.8235 & 0.5182 \\
\hline
\end{tabular}


Table 2: Performance Evaluation of Estimators Using Absolute Bias of Parameter Estimates

\begin{tabular}{|c|c|c|c|c|c|c|c|}
\hline \multirow[t]{2}{*}{ Estimator } & \multirow[t]{2}{*}{ Replication } & \multicolumn{2}{|l|}{$\mathrm{T}=20$} & \multicolumn{2}{|l|}{$\mathrm{T}=30$} & \multicolumn{2}{|l|}{$\mathrm{T}=40$} \\
\hline & & $\alpha_{(1.0)}$ & $\beta_{(0.5)}$ & $\alpha_{(1.0)}$ & $\beta_{(0.5)}$ & $\alpha_{(1.0)}$ & $\beta_{(0.5)}$ \\
\hline \multirow[t]{4}{*}{ OLS } & 10 & 0.8329 & 1.1052 & 1.1045 & 0.6865 & 0.7504 & 0.6310 \\
\hline & 20 & 0.7215 & 1.1602 & 0.8382 & 0.3250 & 0.8247 & 0.7556 \\
\hline & 30 & 0.8444 & 0.9633 & 0.8995 & 0.4047 & 0.7861 & 0.7934 \\
\hline & 40 & 0.9940 & 0.9123 & 0.8621 & 0.4313 & 0.8401 & 0.7819 \\
\hline \multirow[t]{4}{*}{ ILS } & 10 & 0.1246 & 0.0623 & 0.2887 & 0.0879 & 0.0789 & 0.0009 \\
\hline & 20 & 0.0897 & 0.0317 & 0.0039 & 0.0091 & 0.0480 & 0.0115 \\
\hline & 30 & 0.0370 & 0.0078 & 0.0133 & 0.0119 & 0.0603 & 0.0127 \\
\hline & 40 & 0.0619 & 0.0119 & 0.0237 & 0.0049 & 0.0315 & 0.0080 \\
\hline \multirow[t]{4}{*}{2 SLS } & 10 & 0.2272 & 0.0880 & 0.3500 & 0.1225 & 0.0631 & 0.0105 \\
\hline & 20 & 0.2010 & 0.0673 & 0.0876 & 0.0295 & 0.0408 & 0.0005 \\
\hline & 30 & 0.0724 & 0.0192 & 0.0974 & 0.0454 & 0.0260 & 0.0010 \\
\hline & 40 & 0.0229 & 0.0021 & 0.1436 & 0.0556 & 0.0893 & 0.0264 \\
\hline \multirow[t]{4}{*}{ FIML } & 10 & 0.3654 & 0.1115 & 0.2478 & 0.1146 & 0.1045 & 0.0090 \\
\hline & 20 & 0.3256 & 0.0978 & 0.0066 & 0.0228 & 0.0504 & 0.0050 \\
\hline & 30 & 0.1504 & 0.0596 & 0.0027 & 0.0380 & 0.1298 & 0.0069 \\
\hline & 40 & 0.0932 & 0.0371 & 0.0152 & 0.0302 & 0.0908 & 0.0132 \\
\hline
\end{tabular}

Table 3: Performance Evaluation of Estimators Using Root Mean Square Error of Parameter Estimates

\begin{tabular}{|c|c|c|c|c|c|c|c|}
\hline \multirow[t]{2}{*}{ Estimator } & \multirow[t]{2}{*}{ Replication } & \multicolumn{2}{|c|}{$\mathrm{T}=20$} & \multicolumn{2}{|l|}{$\mathrm{T}=30$} & \multicolumn{2}{|l|}{$\mathrm{T}=40$} \\
\hline & & $\alpha_{(1.0)}$ & $\beta_{(0.5)}$ & $\alpha_{(1.0)}$ & $\beta_{(0.5)}$ & $\alpha_{(1.0)}$ & $\beta_{(0.5)}$ \\
\hline \multirow[t]{4}{*}{$\overline{\mathrm{OLS}}$} & 10 & 1.0716 & 1.4008 & 1.3488 & 0.9091 & 0.9022 & 0.8177 \\
\hline & 20 & 1.0079 & 1.6657 & 1.1181 & 1.0362 & 1.0012 & 1.0582 \\
\hline & 30 & 1.0793 & 1.5004 & 1.1243 & 0.9543 & 0.9892 & 1.0995 \\
\hline & 40 & 1.1918 & 1.4628 & 1.1011 & 0.9582 & 1.0239 & 1.0956 \\
\hline \multirow[t]{4}{*}{ ILS } & 10 & 0.5267 & 0.1865 & 0.6066 & 0.1750 & 0.4604 & 0.1338 \\
\hline & 20 & 0.6578 & 0.2298 & 0.5683 & 0.1870 & 0.5019 & 0.1498 \\
\hline & 30 & 0.6833 & 0.2277 & 0.5127 & 0.1657 & 0.5432 & 0.1605 \\
\hline & 40 & 0.6389 & 0.2257 & 0.5382 & 0.1686 & 0.5405 & 0.1522 \\
\hline \multirow[t]{4}{*}{2 SLS } & 10 & 0.5800 & 0.2033 & 0.6404 & 0.2417 & 0.4016 & 0.1400 \\
\hline & 20 & 0.5621 & 0.2098 & 0.6653 & 0.2238 & 0.4949 & 0.1536 \\
\hline & 30 & 0.6849 & 0.2408 & 0.6548 & 0.2167 & 0.4894 & 0.1546 \\
\hline & 40 & 0.6522 & 0.2236 & 0.6675 & 0.2245 & 0.5148 & 0.1543 \\
\hline \multirow[t]{4}{*}{ FIML } & 10 & 0.4842 & 0.1733 & 0.5875 & 0.2342 & 0.5214 & 0.1907 \\
\hline & 20 & 0.5294 & 0.1848 & 0.6164 & 0.2108 & 0.5538 & 0.1834 \\
\hline & 30 & 0.5179 & 0.1864 & 0.5474 & 0.2026 & 0.5873 & 0.1901 \\
\hline & 40 & 0.5240 & 0.1964 & 0.5657 & 0.2064 & 0.5730 & 0.1857 \\
\hline
\end{tabular}


Table 5: Tabular presentation of Optimization Model for Solid Waste Management in Ilorin

\begin{tabular}{|c|c|c|c|c|c|c|}
\hline \multicolumn{2}{|c|}{ Zones based on land use } & $\begin{array}{c}\text { Quantity } \\
\text { of waste } \\
\text { /capita/day } \\
\text { (kg) } \\
\end{array}$ & \multicolumn{2}{|c|}{$\begin{array}{c}\text { No of } \\
\text { vehicles }\end{array}$} & $\begin{array}{c}\text { No of } \\
\text { Ro- } \\
\text { Ro }\end{array}$ & $\begin{array}{l}\text { Manually } \\
\text { loaded } \\
\text { containers } \\
\text { or drums }\end{array}$ \\
\hline \multicolumn{2}{|l|}{ Residential } & 0.13 & \multirow[t]{2}{*}{3} & 4 & 54 & 4 \\
\hline \multicolumn{2}{|c|}{ Administrative } & 0.06 & & - & 8 & - \\
\hline \multirow[t]{2}{*}{ Commercial } & $\begin{array}{l}\text { Store } \\
\text { \&Services }\end{array}$ & 0.08 & \multirow[t]{2}{*}{2} & \multirow[t]{2}{*}{4} & 21 & - \\
\hline & Market & 0.1 & & & 15 & 8 \\
\hline \multirow[t]{2}{*}{ Institution } & Health & 0.01 & \multirow{4}{*}{1} & \multirow{4}{*}{2} & 1 & - \\
\hline & Education & 0.03 & & & 3 & 2 \\
\hline \multicolumn{2}{|l|}{ Transport } & 0.02 & & & 2 & - \\
\hline \multicolumn{2}{|l|}{ Industrial } & 0.05 & & & 4 & - \\
\hline \multicolumn{2}{|l|}{ Total } & 0.48 & 6 & 10 & 108 & 14 \\
\hline
\end{tabular}

Source: Authors' fieldwork. 